\title{
Distribution of factor XIIIa containing cells and collage nous components in radicular cysts: Histochemical and immunohistochemical study
}

\author{
Shubhra Sharma ${ }^{1}$, Sangeeta Patankar ${ }^{2}$. \\ ${ }^{1}$ M.D.S. Lecturer, Terna Dental college and hospital, Navi Mumbai. Maharashtra,India \\ ${ }^{2}$ Prof. \& H.O.D. Y.M.T. Dental College \& Hospital, Navi Mumbai, Maharashtra,India.
}

Correspondence:

D-31,1/4,Sagar Sangam CHS

Sector-4

$\operatorname{Nerul}(W)-400706$.

Navi Mumbai.

(Maharashtra)

E-mail:drshubhra18@gmail.com

Sharma S, Patankar S. Distribution of factor XIIIa containing cells and collage nous components in radicular cysts: Histochemical and immunohistochemical study. J Clin Exp Dent. 2011;3(3):e212-5. http://www.medicinaoral.com/odo/volumenes/v3i3/jcedv3i3p212.pdf

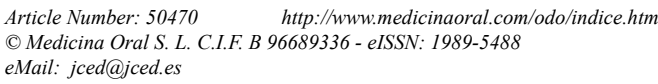

\begin{abstract}
Objective: 1) To differentiate various connective tissue layers in radicular cysts

2) To find the correlation between FXIIIa containing cells and fibrosis.

Factor XIII, fibrin stabilizing factor, stabilizes the clot for blood coagulation and is also responsible for connective tissue organization in healing and tissue repair. FXIIIa has an important role during the process of fibrosis in various lesions, so we conducted a study to find its role in radicular cyst.

Study Design: 10 cases of radicular cyst, reported in our hospital were selected. Clinical and follow up data of those cases were collected from the archives.

Material and Methods: Histochemical analysis with Masson's trichrome was done to differentiate the three layers of radicular cyst. Immunocytochemical staining for distribution of factor XIIIa was carried out. Stained slides were examined under high power. After counting cell, data was analysed statistically.

Results: Positive reaction for Factor XIIIa was observed in certain connective tissue cells in all the layers of radicular cysts. FXIIIa containing cells were numerous in intermediate layer as compared to outer fibrous layer. FXIIIa containing cells and fibrosis was increased in case of radiographically well circumscribed lesion than the diffuse lesion. It can be concluded that factor XIIIa containing cells and collagenous components in radicular cyst play an important role in fibrosis and is also correlated with healing of the lesion.
\end{abstract}

Key Words: Factor XIIIa, radicular cyst, fibrosis, healing. 


\section{Introduction}

Factor XIII is a plasma proenzyme which circulates as a dimer of the active subunit (subunit A) attached to a dimer of the carrier protein (subunit S) factor XIII, also known as fibrin stabilizing factor, stabilizes the clot in final common pathway of blood coagulation. Factor XIII is important not only for blood coagulation but also for connective tissue organization in wound healing and tissue repair. In vitro studies have shown that factor XIIIa can catalyze the crosslinking of fibronection monomers to each other and to type I and type III collagens. This may be important for the stabilization of fibrin clots, as well as during the process of fibrosis in various lesions. Recent immunohistochemical studies have also indicated findings suggesting that the cells containing FXIIIa have an important role during the process of fibrosis in various lesions (1). Since radicular cyst is the most common cyst of the jaws showing varying degrees of fibrosis, it was selected for the present study. Aims and Objectives of the study were :

1) To differentiate various connective tissue layers in radicular cysts.

2) To find the correlation between FXIIIa containing cells and fibrosis.

\section{Material and Methods}

This was retrospective study of ten cases of radicular cyst, diagnosed and treated in Yerala medical trust's dental college and hospital, Navi Mumbai. Clinical and follow up data along with radiographs of those ten cases of radicular cysts were collected from the archives of Department of oral and maxillofacial pathology. The sections from the retrieved paraffin blocks were histologically re-examined for the presence of three distinctive layers in radicular cyst by using hematoxylin and eosin stain. Histochemically the confirmation of all the three layers of radicular cyst was done using Masson's Trichrome staining. Those cases which showed all three layers were included in the study. Paraffin sections of $5 \mu \mathrm{m}$ in thickness were cut and were stained with Masson's trichrome to assist in differentiating the three layers. Immunohistochemical stain for factor XIIIa was employed. Five $\mu \mathrm{m}$ sections were cut from the paraffin blocks and mounted on super frost slides. Immunocytochemical staining was carried out using a streptavidin Avidin-Biotin complex $(\mathrm{ABC})$ labelling technique and visualized with diaminobenzidine tetrahydrochloride (DAB). Sections were dewaxed, washed in alcohol, and antigen was retrieved by microwaving in citric acid $(\mathrm{pH} \mathrm{6)}$ for 30 min. Sections were then washed in phosphate buffered saline (PBS). Endogenous peroxidase was blocked using $1 \%$ hydrogen peroxide in methanol at room temperature for $10 \mathrm{~min}$. Slides were washed in PBS briefly and sections were then washed for $5 \mathrm{~min}$ in PBS followed by the streptavidin-biotin complex Following a wash in
PBS, the peroxidase was then visualised by using 0.18 $\mathrm{g}$ DAB/300 $\mathrm{ml} \mathrm{PBS}$ with $30 \mathrm{ml}$ of hydrogen peroxide for $8 \mathrm{~min}$. Sections were then washed, counterstained with haematoxylin, washed in water and scotts solution, dehydrated and then mounted. Placenta was used as the positive control, and negative controls were prepared by omitting the primary antibody. The pattern of immunostaining for FXIIIa was described as normal when complete cytoplasmic stain was observed. The distribution of factor XIIIa was evaluated by semi quantitative method. Stained slides were examined under high power $(40 \mathrm{x})$ of microscope. Random five high power fields were selected and hundred cells were counted, in each field. After counting cell all the available data was analyzed statistically. Statistical analyses were performed using SPSS 10.0J for Windows. With the help of ANOVA test following parameters were compared.

1) Distribution of FXIIIa containing cells in the all the three layers of radicular cyst.

2) Radiographic appearance of the lesion and FXIIIa containing cells in radicular cyst.

3) Duration of healing and FXIIIa containing cells/fibrosis.

(P-values $<0.05$ were considered to be statistically significant.)

\section{Results}

Distribution of FXIIIa containing cells in three layer of radicular cyst.

Positive reaction for Factor XIIIa was observed in cer-

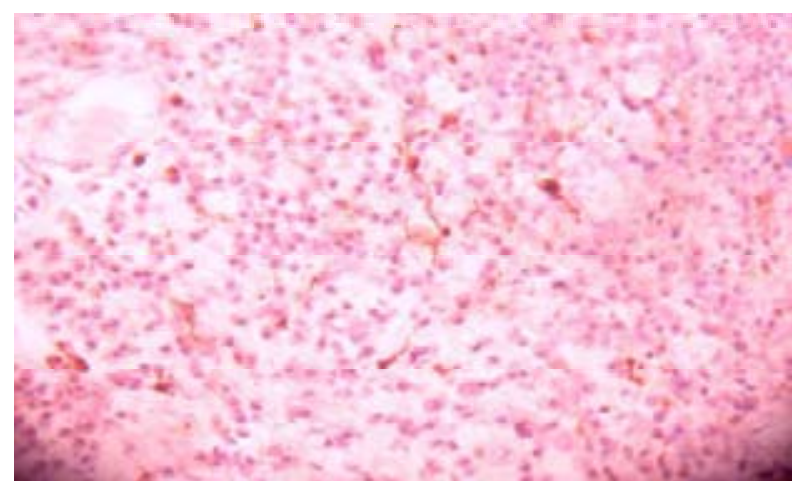

Fig. 1. Innergranulomatous layershowing Factor XIIIacontaining cells.

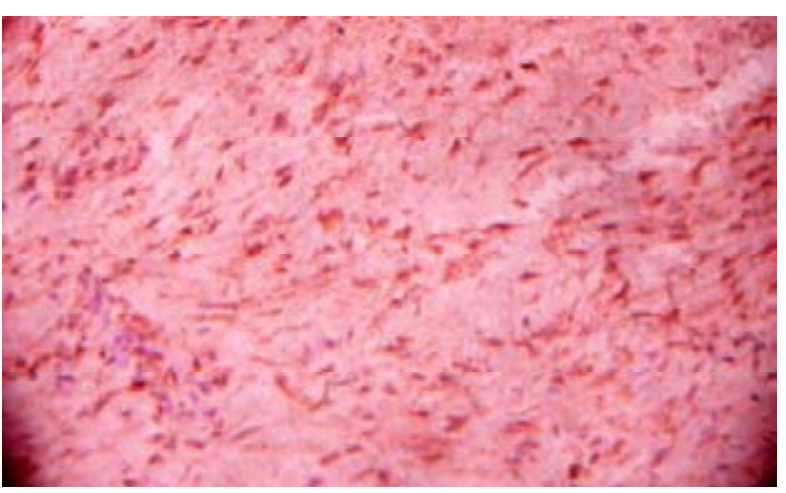

Fig. 2. Intermediate layer showing Factor XIIIa containing cells 
tain connective tissue cells in all the layers of radicular cysts. Distinction between the various layers in the connective tissue capsule of radicular cyst could be clearly seen histochemically. Factor XIIIa containing cells were found to be least in the inner granulomatous layer (Fig.1) and were numerous in the intermediate layer (Fig.2) as compared to outer fibrous layer (Fig.3). All the values

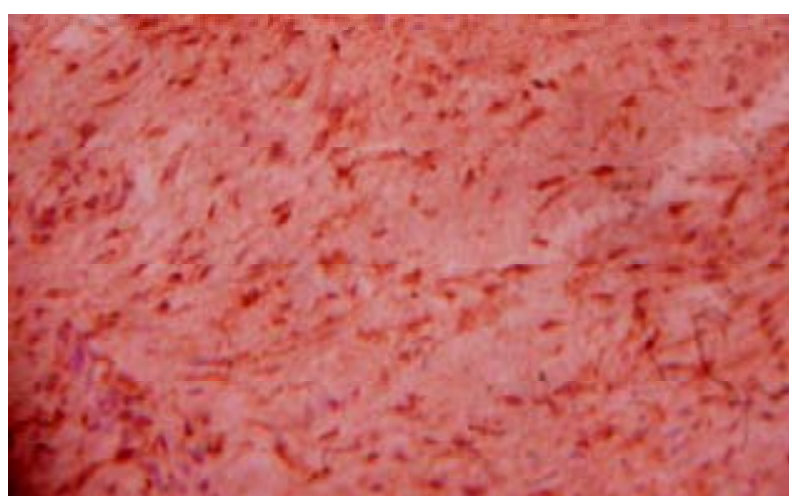

Fig. 3. Outer fibrous layer - Showing Factor XIIIa containing cells.

obtained were subjected for statistical analysis using ANOVA test and it was found statistically significant (p.000) (Table 1).

\begin{tabular}{|c|c|c|c|c|}
\hline Sample No. & $\begin{array}{l}\text { Radiographic } \\
\text { appearance }\end{array}$ & $\begin{array}{l}\text { Amount of } \\
\text { Fibrosis }\end{array}$ & $\begin{array}{l}\text { Positivity for } \\
\text { FXIIla }\end{array}$ & $\begin{array}{l}\text { Duration of } \\
\text { healing based } \\
\text { on radiograph }\end{array}$ \\
\hline 1 & Well circumscribed & Increased & Increased & 4 months \\
\hline 2 & Well circumscribed & Increased & Increased & 3.8 months \\
\hline 3 & Diffuse & Moderate & Moderate & 5.5 months \\
\hline 4 & Well circumscribed & Increased & Increased & 4.5 months \\
\hline 5 & Diffuse & Moderate & Moderate & 5 months \\
\hline 6 & Well circumscribed & Increased & Increased & 3.5 months \\
\hline 7 & Well circumscribed & Increased & Increased & 4 months \\
\hline 8 & Well circumscribed & Increased & Increased & 4.5 months \\
\hline 9 & $\begin{array}{c}\text { No clinical data } \\
\text { available. }\end{array}$ & Increased & Increased & - \\
\hline 10 & $\begin{array}{l}\text { No clinical data } \\
\text { available. }\end{array}$ & Moderate & Moderate & - \\
\hline
\end{tabular}

Table 1. Clinical and radiographic data of all the cases

Radiographic appearance of the lesion and FXIIIa containing cells in radicular cyst

Out of ten cases of radicular cyst, six cases showed well circumscribed radiolucency at the time of diagnosis, two cases showed diffuse radiolucency whereas in two cases radiographic data was not available. FXIIIa containing cells and fibrosis was increased in case of radiographically well circumscribed lesion than the diffuse lesion.

Duration of healing and FXIIIa containing cells and fibrosis

In six out of ten cases showing increases Factor XIIIa cells and fibrosis, the duration of healing was less as compa red to two cases showing less factor XIIIa containing cells and fibrosis.

\section{Discussion}

Factor XIII is a plasma proenzyme which circulates as a dimer of the active subunit (subunit A) attached to a dimer of the carrier protein (subunit S) (1). Factor XIII, also known as fibrin stabilizing factor, stabilizes the clot by cross linking fibrin monomers to each other in final common pathway of blood coagulation (2). Activated Factor XIII can also catalyse the cross linking of fibronectin monomers to each other and to interstitial collagen, as Type I and Type III collagen. Such action is important for, collagen matrix formation in physiologic and pathologic conditions. Factor XIII consisting of a and $b$ subunits in a tetrameric structure. Data accumulated over the past two decades clearly suggest that the role of factor XIII is not restricted to the area of haemostasis and certain findings indicate the possible role of factor XIII in connective tissue organization. Factor XIII is important not only for blood coagulation but also for connective tissue organization in wound healing and tissue repair. Many authors indicated that factor XIIIa containing cells proliferate and differentiate prior to marked fibrosis in various oral and maxillofacial lesions fibrous lesions or granulomatous lesions) such as dilantin gingival hyperplasia, pyogenic granuloma of gingiva, gingival peripheral fibroma, squamous cell carcinoma (3). The results obtained in the present study suggest the conception more strongly.

Our study shows a close relation between the distribution of cells containing FXIIIa and that of collagenous components. Numerous factor XIIIa containing cells were seen not only in the densely fibrous connective tissue layer but also in the moderately to slightly fibrous intermediate layer. The cells were more numerous in the intermediate layer as compared to outer fibrous connective tissue layer. (Graph.1)

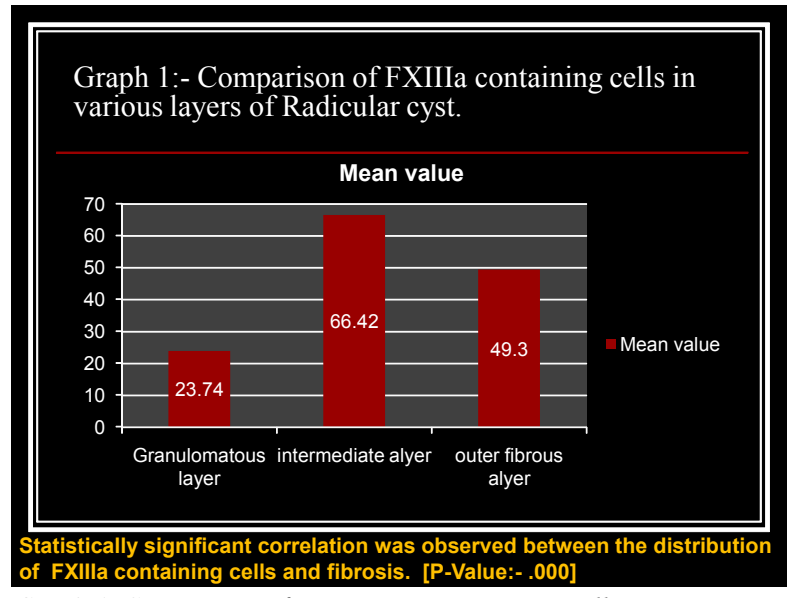

Graph 1. Comparison of Factor XIII containing cells in various layers of radicular cyst.

The stimulatory effect of factor XIII is also reported on fibroblast proliferation Beck et al. (4) 1961. A cellular form of factor XIII consisting exclusively of subunits 
has also been shown in platelets and monocytes, though the function of the intracellular factor is not fully known. The impaired wound healing of patients deficient in factor XIII and its stimulatory effect on fibroblast proliferation have been known for a long time. It was also shown that fibronectin and collagen serve as substrates for factor XIII. Fear et al. showed that both subunits of factor XIII were present in cells of different connective tissues, and without immunomorphological or enzyme cytochemical characterization, they interpreted these cells as fi broblasts(5)

Leibivich et al. (6) hypothesized that macrophage promote fibroblast proliferation through the production of a factor or factors. More recently Adany et al. demonstrated the co-expression of factor XIIIa with monocytes and macrophage differentiation marker antigens including mononuclear leucocyte marker (Leu-M3), mature phagocyte marker (RFD7) and human leucocyte antigen DR-1 (HLA-DR) in various tissue by double immunofluorescent labelling technique (7). These findings suggest that FXIIIa containing cells belong to the monocytes/macrophage cell line including tissue macrophages (histiocytes). Adany et al. have also shown that factor XIIIa was retained during the differentiation of monocytes into macrophages. Toida et al. (7) suggested that FXIIIa-containing cells existing in the radicular cyst walls could be histiocytic. As histiocytes (tissue macrophages) belong to the mononuclear phagocyte system and are generally considered to be derived from circulating blood monocytes, it seemed reasonable that connective tissue macrophages also express factor XIII subunit a. If FXIIIa-containing interstitial cells are tissue macrophages (histiocytes), their intracellular FXIIIa could be one such factor.

The characteristic of factor XIIIa containing interstitial cells have not yet been made sufficiently clear. In the more fibrous lesions, however, these cells were markedly increased in number and were dendritic or stellate in shape (8). In the present study, it was observed that there

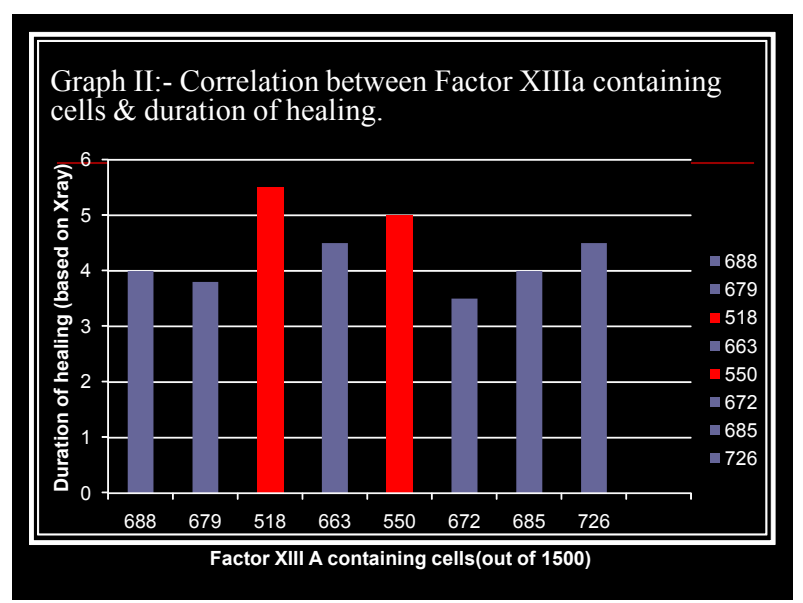

Graph 2. Correlation between factor XIIIa containing cells and duration of healing was an increase in FXIIIa containing cells and fibrosis with less duration for healing of the lesion. The correlation of all the observations of clinical data with the amount of fibrosis in radicular cyst suggests that number of FXIIIa containing cells and fibrosis can be related to the healing of the lesion (Graph 2). However, furthermore precise characterization of this FXIIIa-containing cell population is needed, and is the issue to be addressed next.

\section{References}

1. Toida M, Watanabe F, Tsai CS, Okutomi T, Tatematsu N, Oka N. Factor XIIIa -containing cells and fibrosis in oral and maxillofacial lesions:an immunohistochemical study. Oral Surg Oral Med Oral Pathol. 1989;68:293-9.

2. Lorand L. Introduction to clotting and lysis in blood plasma. Methods Enzymol. 1976;45:31-7.

3. Kesaki-Oja , Mosher DF, Vaheri A. Cross-linking of major fibroblast surface-associated glycoprotein (fibronectin) catalysed by blood coagulation factor XIII. Cell. 1976;9:29-35.

4. Beck.E, Duckert J, Ernst M. The influence of fibrin stabilizing factor on the growth of fibroblast in vitro and wound healing. Thromb Diath hemorrh. 1961;6:485-91.

5. Fear JD.et.al, Localisation of factor XIII in human tissues using immunoperoxidase technique. J Clin Pathol. 1984; 37,560-3.

6. Leibovich SJ, Ross R. The role of the macrophage in wound repair. A study with hydrocortisone and antimacrophage serum. Am J Pathol. 1975:78; 71-100.

7. Toida M, Tsai CS, Okumura Y, Tatematsu N, Oka N. Distribution of factor XIIIa - containing cells and collagenous components in radicular cysts: histochemic and immunohistochemic studies. J Oral Pathol Med. 1990:19;155-9.

8. Adány R, Belkin A, Vasilevskaya T, Muszbek L. Identification of blood coagulation factor XIII in human peritoneal macrophages. Eur J Cell Biol. 1985:38;171-3. 